\title{
Efektivitas Media Pembelajaran Berbasis Android pada Mata Pelajaran Perawatan Wajah, Badan (Body Massage) dan Waxing di SMK
}

\section{Bayu Abiyoga ${ }^{1 *}$, Rahmiati2}

1,2 Universitas Negeri Padang, Padang, Indonesia

\section{ART I CLE I N F O}

\section{Article history:}

Received August 12, 2021

Revised August 13, 2021

Accepted November 19, 2021

Available online December 25, 2021

Kata Kunci:

Media Pembelajaran, Android,

Model Pengembangan 4D

Keywords:

Learning Media, Android, $4 D$ Development Model

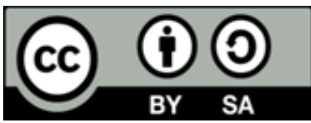

This is an open access article under the CC BY-SA license.

Copyright (ㄷ) 2021 by Author. Published by Universitas Pendidikan Ganesha.

\begin{abstract}
A B S T R A K
Permasalahan yang sering terjadi di lapangan adalah kurangnya sarana prasarana penunjang peserta didik dalam proses belajar mandiri dan belum tersediannya aplikasi yang dapat diakses dan daring di kelas XI SMK. Penelitian ini bertujuan untuk mengembangkan produk berupa media pembelajaran berbasis Android yang valid, praktis, dan efektif pada mata pelajaran perawatan wajah, badan (body massage), dan waxing. Pengembangan media pembelajaran berbasis Android menggunakan metode penelitian R\&D dengan prosedur pengembangan 4D (define, design, development, dan deseminate). Subjek yang terlibat dalam penelitian ini adalah peserta didik kelas XI SMK. Hasil penelitian menunjukkan kelayakan media pembelajaran berbasis Android dengan hasil uji ahli media diperoleh rata rata $89 \%$ dengan kategori valid. Hasil uji ahli materi diperoleh rata-rata sebesar $91 \%$ dengan kategori valid. Hasil uji angket praktikalitas guru diperoleh rata-rata 94,44 dengan kategori sangat praktis. Hasil uji angket praktikalitas peserta didik diperoleh rata-rata $76,54 \%$ dengan kategori praktis. Berdasarkan hasil temuan penelitian di atas di simpulkan bahwa media pembelajaran berbasis Android ini valid, praktis dan efektif untuk dimanfaatkan sebagai media pembelajaran pada mata pelajaran perawatan wajah, badan (body massage), dan waxing di SMK. Diharapkan kepada guru agar lebih inovatif dan kreatif mempergunakan media pembelajaran.
\end{abstract}

\section{A B S T RA CT}

Problems that often occur in the field are the lack of student support infrastructure for students in the independent learning process, the unavailability of accessible and online applications in class XI SMK. This study aims to develop a product in the form of an Android-based learning media that is valid, practical, and effective in the subjects of facial, body care (body massage) and waxing. The development of learning media based on Android uses R\&D research methods with $4 D$ development procedures (define, design, development, and disseminate). The subjects involved in this study were students of class XI SMK. The results showed the feasibility of Android-based learning media with media expert test results obtained an average of $89 \%$ in the valid category. The results of the material expert test obtained an average of $91 \%$ with a valid category. The results of the teacher's practicality questionnaire test obtained an average of 94.44 with a very practical category. The results of the practicality questionnaire of students obtained an average of $76.54 \%$ in the practical category. Based on the findings of the research above, it is concluded that this Android-based learning media is valid, practical, and effective to be used as a learning medium in the subjects of facial, body massage, and waxing in SMK. It is hoped that teachers will be more innovative and creative in using learning media.

\section{PENDAHULUAN}

Kurikulum SMK diorganisasikan ke dalam komponen yang bersifat normatif yang berperan dalam pembentukan watak manusia Indonesia, adaptif yang berperan dalam penanaman dasar dan pengembangan kemampuan profesi serta produktif yang berperan dalam pembelajaran pengetahuan dan 
keterampilan produktif sesuai dengan kebutuhan dunia kerja (Basori, 2013; Siswanto, 2012). Mata pelajaran dasar kejuruan terdiri atas beberapa bentukan kompetensi kejuruan dengan pengembangan kemampuan menyesuaikan diri dalam bidang keahliannya (Duma et al., 2021; Setiadi, 2019). Mata pelajaran produktif sesuai kurikulum SMK yaitu: dasar dasar kecantikan dan spa, perawatan tangan, kaki dan rias wajah kreatif, pemangkasan dan pewarnaan rambut, pengeritingan dan pelurusan rambut, penataan sanggul modern dan kreatif dan perwatan wajah dan badan (body massage) dan waxing. Dari semua mata pelajaran di atas, dipilih perawatan wajah, badan (body massage), dan waxing. Dari indikator pencapaian, kompetensi pengetahuan yang diharapkan menjelaskan pengertian massage (pengurutan badan), menjelaskan tujuan massage (pengurutan badan), menguraikan gerakan pokok massage, menentukan bahan dan kosmetika massage (pengurutan badan), membedakan metode massage (pengurutan badan), menganalisis pengurutan badan dengan berbagai metode massage sedangkan keterampilan menyiapkan bahan dan kosmetika massage (pengurutan badan) sesuai dengan fungsinya, melakukan massage (pengurutan badan) sesuai dengan metode dan tujuan massage.

Pembelajaran saat covid 19 mewabah di Indonesia mengubah semuanya, khususnya pendidikan (Diningrat et al., 2020; Perrotta \& Bohan, 2020). Pembelajaran di sekolah berlangsung melalui sistem daring. Pembelajaran daring adalah sebagai kata online yang sering kita gunakan dalam kaitan teknologi internet. Pembelajaran daring artinya adalah pembelajaran yang dilakulan online dari jarak jauh menggunakan aplikasi pembelajaran daring merupakan pembelajaran yang dilakukan tanpa tatap muka (Agustin et al., 2021; Rosyada et al., 2021). Sistem pembelajaran melalui daring dibantu beberapa aplikasi, seperti google classroom, google meet, edmodo, dan zoom (Basilaia \& Kvavadze, 2020; Naserly, 2020). Menggunakan aplikasi ini saat pandemi untuk belajar peserta didik, belajar kurang efektif, sering terjadi jaringan lemot, kouta internet terbatas, dan KBM kurang efektif (Magdalena et al., 2020; Rigianti, 2020). Pembelajan daring ini bertujuan agar pembelajaran di saat pandemi harus berjalan walaupun tidak efektif dengan alasan jaringan kuota yang terbatas. Saat ini, media menggunakan internet untuk pembelajaran menggunakan media sangat penting (Wijayanengtias \& Claretta, 2020).

Penggunaan media dan sumber belajar merupakan bagian dari komponen yang memengaruhi pembelajaran (Rakhman et al., 2017; Sintia et al., 2015). Bahan ajar perlu disesuaikan dengan kondisi siswa dan strategi pembelajaran yang digunakan oleh guru. Berhasilnya suatu tujuan pembelajaran bergantung pada proses belajar mengajar yang di alami siswa (Arum \& Wahyudi, 2016; Wahyuni, 2018). Seorang guru dituntut untuk teliti dalam memilih metode mengajar yang sesuai dengan tujuan yang ingin dicapai, juga mampu memilih media yang sesuai dengan materi dan mempermudah menyampaikan materi (Koswara \& Rasto, 2016; Walid et al., 2013). Media pembelajaran merupakan pembawa pesan atau informasi yang bertujuan sebagai instruksional dengan maksud pengajaran antarsumber dan penerima materi pembelajaran (Arsyad, 2014). Media pembelajaran yang efektif akan menentukan tersampainya informasi pembelajaran dengan baik kepada siswa, sehingga nantinya akan memengaruhi capaian hasil belajar siswa. Media pembelajaran yang menggabungkan pengalaman konkret membantu peserta didik menggabungkan pengalaman sebelumnya, sehingga mempermudah mempelajari konsep- konsep abstrak (Parlindungan et al., 2020).

Permasalahan media pembelajaran di sekolah, yaitu guru mengajar sebagian besar masih menggunakan papan tulis, modul, dan catatan dari guru. Guru mengajar menggunakan teknik mengajar secara manual. Hal ini menangakibatkan siswa seringkali bosan dan bolos sekolah. Kondisi seperti ini juga berpengaruh pada nilai pengetahuan dan keterampilan siswa. Permasalahan lainnya, yaitu sarana prasarana untuk memfasilitas guru mengajar masih kurang seperti infokus. Dipilihnya masalah ini pada mata pelajaran perawatan wajah, badan (body massage), dan waxing sangat tepat karena siswa lebih condong tertarik ke mata pelajaran tersebut untuk belajar dan membuka usaha. Mata pelajaran media pembelajaran sedapat mungkin diterapkan, khususnya pada mata pelajaran perawatan wajah, badan (body massage), dan waxing di kelas XI TKC dengan kompetensi dasar melakukan pengurutan badan dengan berbagai metode massage dan melakukan dengan media berbasis android (teknologi). Pembelajaran berbasis masalah diawali dengan penyuguhan berbagai masalah yang nyata yang dapat berfungsi sebagai sarana untuk melakukan penyelidikan, terlebih dahulu peserta didik diberikan sebuah masalah untuk diinvestigasi dan analisis untuk mencari solusinya (Narmaditya et al., 2018; Shinde \& Inamdar, 2013). Pembelajaran berbasis masalah berperan sebagai strategi instruksional yang mendukung belajar aktif, strategi dapat dipakai sebagai kerangka pengembangan suatu modul, kursus, program, atau kurikulum (Alfianiawati et al., 2019; Amini et al., 2019).

Pengembangan media pembelajaran, khususnya berbasis android merupakan media pendukung pembelajaran saat ini yang terpopular (Muyaroah \& Fajartia, 2017). Media pembelajaran berbasis android akan menjadi alat sarana atau alat bantu pembelajaran yang efektif dalam pemanfaatan smartphone android sebagai media pembelajaran saat guru rapat atau pelatihan di luar kota. Guru bisa mengintruksikan atau memberi informasi lewat pembelajaran berbasis android yang akan dipelajari 
karena di SMK N 4 Kota Jambi belum ada media pembelajaran berbasis android. Android memiliki kelebihan yaitu User friendly, yang dimaksudkan disini adalah system. Android sangat mudah untuk dijalankan (Ilmadi et al., 2020; Setiyoaji et al., 2020). Keunggulan lainnya terdapat dari segi tampilan system android yang menarik dan tidak kalah baiknya dengan iOs (apple). Hal ini dikarenakan dari awal, android mengusung konsep dan teknologi iOs hanya saja android merupakan versi murah dari iOs. Sistem operasi ini memang memiliki konsep open source yang mana pengguna dapat bebas mengembangkan system android versi miliknya sendiri. Sehingga akan banyak sekali costume ROM yang bisa anda gunakan.

Penelitian ini bertujuan untuk mengembangkan media pembelajaran berbasis android pada mata pelajaran perawatan wajah, badan, (body massage), dan waxing dengan kompetensi dasar melakukan pengurutan badan dengan berbagai metode pada kelas XI TKC. Media pembelajaran berbasis android akan lebih praktis dilakukan di mana pun dan kapan pun, sehingga dapat membuat peserta didik lebih mudah dalam belajar.

\section{METODE}

Penelitian yang dilakukan peneliti merupakan jenis penelitian pengembangan atau Research and Development (R\&D). Penelitian R\&D dalam pendidikan merupakan suatu proses yang digunakan untuk mengembangkan dan mengetahui validitas suatu aplikasi (Sugiyono, 2014). Jadi, penelitian pengembangan yang akan dilakukan adalah pengembangan media pempelajaran berbasis android pada mata pelajaran perawatan wajah,badan (body massage), dan waxing di SMK N4 KOTA JAMBI. Pengembangan model pembelajaran ini dikembangkan pada mata pelajaran perawatan wajah, badan (body massage), dan waxing. Pada mata pelajaran ini muncul pada semester genap di SMK N4 KOTA JAMBI. Prosedur pengembangan yang dilakukan pada penelitian ini adalah model ADDIE (Analysis, Design, Development, Implementation, Evaluation) yang dikembangkan oleh Dick and Carry (1996).

Tahap validasi bertujuan untuk memvalidasi dan menilai kelayakan dari produk. Validasi produk melalui beberapa tenaga ahli yang memiliki pengalaman dalam bidangnya. Validasi dilakukan terhadap aspek materi berbasis Android sesuai dengan kompetensi dasar. Validasi aspek media dilakukan dengan pengisian lembar angket validasi yang melibatkan validator dari dosen pascasarjana Pendidikan Teknologi Kejuruan, Dosen FPP UNP, dan guru SMK N4 Kota Jambi dengan tujuan untuk melihat desain, materi dari media sesuai dengan aspek-aspek pengembangan media pembelajaran. Tujuan akhir dari validasi oleh validator adalah untuk merevisi media pembelajaran yang dikembangkan. Saran perbaikan dari validator yang dijadikan patokan dalam perbaikan untuk dibuat sebelum uji coba. Tahapan praktikalitas bertujuan untuk memperoleh data dari angket yang diberikan dengan tujuan untuk melihat kepraktisan media pembelajaran berbasis Android pada materi kabel- intekoneksi, instalasi home theater dan instalasi car audio system. Nilai praktikalitas untuk mengetahui tingkat kepraktisan produk saat digunakan oleh subjek peneliti. Angket praktikalitas untuk guru diisi oleh guru mata pelajaran dari SMK N4 Kota Jambi yang meliputi aspek kemudahan penggunaan media, efektifitas waktu, penggunaan media. Data yang diperoleh dianalisis sehingga diperoleh tingkat kepraktisan. Selain itu, praktifitas diperoleh dari tanggapan peserta didik kelas XI TKC SMK N4 Kota Jambi. Peserta didik mengisi angket respon praktifitas yang meliputi aspek kemudahan, waktu, dan mafaat media. Rata rata persentase yang diperoleh menjadi patokan dalam perolehan tingkat kepraktisan media pembelajaran yang dikembangkan.

Tahap uji efektivitas dilakukan dengan tujuan untuk mengukur keefektifan produk. Instrumen tes hasil belajar pada post test digunakan untuk mengukur keefektifan produk yang diterapkan pada kelas kontrol dan kelas eksperimen. Kelas control dengan pembelajaran konvensional tanpa diberikan media pembelajaran berbasis android. Berdasarkan hasil tes tersebut terlihat persentase ketuntasan peserta didik dengan memedomani kurikulum SMK N4 Kota Jambi yang telah ditetapkan, sehingga memperoleh media yang sesuai dengan materi dan user interface yang digunakan pada media tersebut.

\section{HASIL DAN PEMBAHASAN}

\section{Hasil}

\section{Uji Validitas Media}

Sebelum pengujicobaan produk pembelajaran yang dikembangkan, maka perlu dilakukan revisi media pembelajaran berbasis Android. Berdasarkan hasil saran dari validator, revisi terhadap media pembelajaran berbasis Android dilakukan. Tujuan revisi produk untuk kesempurnaan pembelajaran metode massage (pengurutan badan), sehingga menjadi media pembelajaran yang valid, praktis, dan efektif. Revisi/perbaikan dilaksanakan pada semua aspek, antara lain aspek media, dan materi seperti yang tersaji pada Tabel 1 . 
Tabel 1. Hasil Validasi Ahli

\begin{tabular}{|c|c|c|c|}
\hline No & Ahli & Sebelum Revisi & Sesudah Revisi \\
\hline 1 & Ahli Media & $\begin{array}{l}\text { Tampilan video masih terlalu besar saat } \\
\text { ditampilkan melalui android } \\
\text { Ukuran tampilan tidak pada KI KD perlu di } \\
\text { sesuaikan dengan ukuran android }\end{array}$ & $\begin{array}{l}\text { Tampilan sudah sesuai } \\
\text { tampilan android } \\
\text { Ukuran tampilan KI KD sudah } \\
\text { sesuai }\end{array}$ \\
\hline 2 & Ahli Materi & $\begin{array}{l}\text { Sebaiknya ditambah juga dengan materi } \\
\text { massage yang lain agar lebih lengkap } \\
\text { Sebaiknya ditambah video pengurutan badan } \\
\text { secara modern }\end{array}$ & $\begin{array}{l}\text { Materi massage sudah } \\
\text { ditambahkan } \\
\text { Video pengurutan badan secara } \\
\text { modern sudah ditambah }\end{array}$ \\
\hline
\end{tabular}

\section{Uji Efektivitas Ketuntasan Klasikal}

Efektivitas penggunaan media pembelajaran ditinjau dengan dua cara yaitu, melihat ketercapaian Kriteria Ketuntasan Minimum (KKM) secara klasikal dan dengan menghitung data pretest dan posttest menggunakan Gain Score. Ketuntasan klasikal dilihat dari persentase dari jumlah peserta didik yang tuntas di kelas eksperimen dan di kelas kontrol. Dasar untuk menentukan efektivitas media pembelajaran berbasis android adalah persentase klasikal peserta didik lebih besar atau sama dngan 85\% maka media pembelajaran berbasis android mata pelajaran perawatan wajah, badan (body massage), dan waxing efektif digunakan. Tabel 2 menunjukkan hasil rata-rata nilai peserta didik pada mata pelajaran tersebut.

Tabel 2. Ketuntasan Klasikal Peserta Didik Kelas XI TKC

\begin{tabular}{cllcc}
\hline No & \multicolumn{1}{c}{ Kelas } & KKM & Persen Ketuntasan (\%) \\
\hline \multirow{3}{*}{1} & Eksperimen (Media Pembelajaran & $<75$ & 85 & - \\
& Berbasis Android) & $\geq 75$ & 15 & 100 \\
\cline { 2 - 5 } & & Jumlah Peserta = 20 & 38,9 \\
\cline { 2 - 5 } 2 & Kontrol (Media Pembelajaran & $<75$ & 94,5 & 61,1 \\
\cline { 2 - 5 } & Konvensional) & $\geq 75$ & 5,5 & \\
\cline { 2 - 5 } & & Jumlah Peserta Didik = 18 &
\end{tabular}

Dari hasil yang ditunjukkan pada Tabel 2, diperoleh jumlah peserta didik yang tuntas secara klasikal di kelas eksperimen sebanyak 20 peserta didik (100\%) bila dibandingkan dengan ketuntasan klasikal di kelas kontrol hanya 11 dari 18 peserta didik (61,1\%). Kondisi ini memperlihatkan ketuntasan klasikal sudah tercapai.

\section{Uji Efektivitas Ditinjau dari Analisis Hasil Pretest-Posttest}

Setelah mengetahui hasil analisis pretest dan posttest, didapatkan analisis perbedaan hasil pretest dan posttest dengan data terlihat pada Tabel 3.

Tabel 3. Perbedaan Hasil Pretest dan Posttest

\begin{tabular}{lccc}
\hline \multicolumn{1}{c}{ Hasil } & Nilai Maksimal & Nilai Minimal & Rata-Rata \\
\hline Pretest & 75 & 30 & 54,80 \\
Posttest & 90 & 50 & 77,80 \\
\hline \multicolumn{4}{c}{ Selisih Nilai Rata-Rata Pretest dan Posttest } \\
\hline Gain Score & 71,43 & 16,67 & $\mathbf{2 3 , 0 0}$ \\
Klasifikasi Gain Score & Tinggi & Rendah & 51,85 \\
\hline
\end{tabular}

Hasil analisis yang diperoleh di Tabel 3 menunjukkan bahwa terjadi peningkatan rata-rata nilai peserta didik sebesar 23,00. Analisis nilai gain score didapatkan nilai minimal adalah 16,67 dengan klasifikasi rendah, nilai gain score maksimal 71,43 dengan klasifikasi tinggi, dan nilai rata-rata dari gain score diperoleh sebesar 51,85 dengan klasifikasi sedang. Dengan perolehan peningkatan hasil belajar peserta didik sebesar 23,00 dan gain score bernilai dan 51,85 maka, efektivitas produk bisa dikatakan sangat baik digunakan dalam kegiatan pembelajaran.

\section{Pembahasan}

Penggunaan media dan sumber belajar merupakan bagian dari komponen yang memengaruhi pembelajaran (Rakhman et al., 2017; Sintia et al., 2015). Bahan ajar perlu disesuaikan dengan kondisi siswa dan strategi pembelajaran yang digunakan oleh guru, berhasilnya suatu tujuan pembelajaran 
bergantung pada proses belajar mengajar yang di alami siswa (Arum \& Wahyudi, 2016; Wahyuni, 2018). Seorang guru dituntut untuk teliti dalam memilih metode mengajar yang sesuai dengan tujuan yang ingin dicapai, juga mampu memilih media yang sesuai dengan materi untuk mempermudah menyampaikan materi (Koswara \& Rasto, 2016; Walid et al., 2013). Media pembelajaran merupakan pembawa pesan atau informasi yang bertujuan sebagai instruksional dengan maksud pengajaran antar sumber dan penerima materi pembelajaran (Arsyad, 2014). Media pembelajaran yang efektif akan menentukan tersampainya informasi pembelajaran dengan baik kepada siswa sehingga nantinya akan mempengaruhi capaian hasil belajar siswa. Media pembelajaran yang menggabungkan pengalaman konkrit membantu peserta didik untuk menggabungkan pengalaman sebelumnya sehingga mempermudahnya untuk mempelajari konsepkonsep abstrak (Parlindungan et al., 2020).

Permasalahan media pembelajaran di sekolah yaitu guru mengajar sebagian besar masih menggunakan papan tulis, modul dan catatan dari guru, siswa seringkali bosan dan bolos sekolah dengan guru mengajar menggunakan teknik mengajar secara manual. Dan juga berpengaruh ke nilai pengetahuan dan keterampilan. Tidak hanya dengan teknik mengajar saja permasalahannya, sarana prasarana untuk memfasilitas guru mengajar masih kurang seperti infokus. Diangkatnya masalah ini dan memilih mata pelajaran perawatan wajah, badan (body massage), dan waxing merupakan pilihan yang tepat karena siswa lebih condong tertarik ke mata pelajaran tersebut untuk belajar dan membuka usaha. Untuk mata pelajaran dari media pembelajaran sedapat mungkin diterapkan khususnya pada mata pelajaran perawatan wajah, badan (body massage) dan waxing di kelas XI TKC dengan kompetensi dasar melakukan pengurutan badan dengan berbagai metode massage dan melakukan dengan media berbasis android (teknologi). Pembelajaran berbasis masalah diawali dengan penyuguhan berbagai masalah yang nyata yang dapat berfungsi sebagai sarana untuk melakukan penyelidikan, terlebih dahulu peserta didik diberikan sebuah masalah untuk diinvestigasi dan analisis untuk mencari solusinya (Narmaditya et al., 2018; Shinde \& Inamdar, 2013). Pembelajaran berbasis masalah berperan sebagai strategi instruksional yang mendukung belajar aktif, strategi dapat dipakai sebagai kerangka pengembangan suatu modul, kursus, program atau kurikulum (Alfianiawati et al., 2019; Amini et al., 2019).

Pengembangan media pembelajaran khususnya berbasis android merupakan media pendukung pembelajaran saat ini yang terpopular (Muyaroah \& Fajartia, 2017). Media pembelajaran berbasis android akan menjadi alat sarana atau alat bantu pembelajaran yang efektif dalam pemanfaatan smartphone android sebagai media pembelajaran saat guru rapat atau pelatihan di luar kota guru bisa mengintruksikan atau memberi informasi lewat pembelajaran berbasis android yang akan di pelajari dikarenakan di SMK N 4 Kota Jambi belum ada media pembelajaran berbasis android. Android memiliki kelebihan yaitu: User friendly, yang dimaksudkan disini adalah system. Android sangat mudah untuk dijalankan (Ilmadi et al., 2020; Setiyoaji et al., 2020). Keunggulan lainnya terdapat dari segi tampilan system android yang menarik dan tidak kalah baiknya dengan iOs (apple). Hal ini dikarenakan dari awal, android mengusung konsep dan teknologi iOs hanya saja android merupakan versi murah dari iOs. Sistem operasi ini memang memiliki konsep open source, sehingga pengguna dapat bebas mengembangkan system android versi miliknya sendiri. Dengan demikian, akan banyak sekali costume ROM yang bisa digunakan.

\section{SIMPULAN}

Hasil uji efektivitas media pembelajaran berbasis Android diperoleh berdasarkan nilai pretest dan posttest dari peserta didik setelah menggunakan media pembelajaran berada dalam kategori efektif. Media pembelajaran perawatan wajah, badan (body massage), dan waxing berbasis Android yang dikembangkan dapat dipakai dalam proses pembelajaran guna meningkatkan hasil belajar peserta didik. Penelitian pengembangan ini yang menjadi subjek untuk uji coba adalah peserta didik kelas XI TKC SMK N4 Kota Jambi.

\section{DAFTAR RUJUKAN}

Agustin, M., Puspita, R. D., Nurinten, D., \& Nafiqoh, H. (2021). Tipikal Kendala Guru PAUD dalam Mengajar pada Masa Pandemi Covid 19 dan Implikasinya. Jurnal Obsesi : Jurnal Pendidikan Anak Usia Dini, 5(1), 334-345. https://doi.org/10.31004/obsesi.v5i1.598.

Alfianiawati, T., Desyandri, \& Nasrul. (2019). Pengaruh Penggunaan Model Problem Based Learning terhadap Hasil Belajar Siswa dalam Pembelajaran ISD di Kelas V SD. Ejournal Pembelajaran Inovasi: Jurnal Ilmiah Pendidikan Dasar, 7(3), 1-10. http://ejournal.unp.ac.id/students/index.php/pgsd/article/view/5400.

Amini, R., Setiawan, B., Fitria, Y., \& Ningsih, Y. (2019). The Difference of Students Learning Outcomes using 
the Project-Based Learning and Problem-Based Learning Model in Terms of Self-Efficacy. Journal of Physics: Conference Series, 1387(1). https://doi.org/10.1088/1742-6596/1387/1/012082.

Arsyad, A. (2014). Media Pembelajaran. PT. Rajagrafindo Persada.

Arum, T. S., \& Wahyudi, W. (2016). Pengembangan Modul Pembelajaran Tematik Integratif Subtema Hubungan Makhluk Hidup dalam Ekosistem Pendekatan Saintifik Untuk Kelas 5 Sd. Scholaria: $\begin{array}{lllll}\text { Jurnal Pendidikan } & \text { Dan }\end{array}$ https://doi.org/10.24246/j.scholaria.2016.v6.i3.p239-250.

Basilaia, G., \& Kvavadze, D. (2020). Transition to Online Education in Schools during a SARS-CoV-2 Coronavirus (COVID-19) Pandemic in Georgia. Pedagogical Research, 5(4), 1-9. https://doi.org/10.29333/pr/7937.

Basori. (2013). Pemanfaatan Social Learning Network "Edmodo" dalam Membantu Perkuliahan Teori Bodi Otomotif di Prodi PTM JPTK FKIP UNS. Jurnal Ilmiah Pendidikan Teknik Dan Kejuruan, 6(2), 99105. https://doi.org/10.20961/jiptek.v6i2.12562.

Diningrat, S. W. M., Nindya, M. A., \& Salwa, S. (2020). Emergency Online Teaching: Early Childhood Education Lecturers' Perception of Barrier and Pedagogical Competency. Jurnal Cakrawala Pendidikan, 39(3), 705-719. https://doi.org/10.21831/cp.v39i3.32304.

Duma, S., Limbong, M., \& Kailola, L. G. (2021). Pengaruh Kompetensi Profesional Guru, Motivasi Belajar terhadap Hasil Belajar Siswa di Sekolah Menengah Kejuruan Kristen. Jurnal Pendidikan Tambusai, 5, 815-826. https://www.jptam.org/index.php/jptam/article/view/1036.

Ilmadi, Zarista, R. H., Aden, \& Sastro, G. (2020). The Effectiveness of Online Learning for Mathematics Students During the Covid-19 Pandemic (Case Study-Mathematics Study Program, Pamulang University). Jurnal Cendekia: Jurnal Pendidikan Matematika, 4(2), 1273-1282. https://doi.org/10.31004/cendekia.v4i2.372.

Koswara, K., \& Rasto, R. (2016). Kompetensi dan Kinerja Guru Berdasarkan Sertifikasi Profesi. Jurnal Pendidikan Manajemen Perkantoran, 1(1), 61. https://doi.org/10.17509/jpm.v1i1.3269.

Magdalena, I., Yuliani, T., Kurniawan, I., \& Arief, S. (2020). Kendala Pembelajaran Jarak Jauh secara Daring pada Guru Sekolah Dasar di SD Al Fattaah. PENSA : Jurnal Pendidikan Dan Ilmu Sosial, 2(3), 298306. https://doi.org/https://doi.org/10.36088/pensa.v2i3.966.

Muyaroah, S., \& Fajartia, M. (2017). Pengembangan Media Pembelajaran Berbasis Android dengan menggunakan Aplikasi Adobe Flash CS 6 pada Mata Pelajaran Biologi. Innovative Journal of Curriculum and Educational Techology, 6(2), 22-26. https://doi.org/10.15294/ijcet.v6i2.19336.

Narmaditya, B. S., Wulandari, D., \& Sakarji, S. R. B. (2018). Does Problem-based Learning Improve Critical Thinking Skills? Cakrawala Pendidikan, 37(3), 378-388. https://journal.uny.ac.id/index.php/cp/article/view/21548.

Naserly, M. K. (2020). Implementasi Zoom, Google Classroom, dan Whatsapp Group dalam Mendukung Pembelajaran Daring (Online) pada Mata Kuliah Bahasa Inggris Lanjut. Journal of Chemical Information and Modeling. http://aksarapublic.com/index.php/home/article/view/417.

Parlindungan, D. P., Mahardika, G. P., \& Yulinar, D. (2020, October). Efektivitas Media Pembelajaran Berbasis Video Pembelajaran dalam Pembelajaran Jarak Jauh (PJJ) di SD Islam An-Nuriyah. In Prosiding Seminar Nasional Penelitian LPPM UMJ (Vol. 1, No. 1). https://doi.org/https: https:// https://jurnal.umj.ac.id/index.php/semnaslit/article/view/8793.

Perrotta, K. A., \& Bohan, C. H. (2020). A Reflective Study of Online Faculty Teaching Experiences in Higher Education. Journal of Effective Teaching in Higher Education, 3(1), 50-66. https://doi.org/10.36021/jethe.v3i1.9.

Rakhman, K. A., Saraha, A. R., \& Sugrah, N. (2017). Pengembangan Video Penggunaan Alat Gelas Laboratorium Kimia di Universitas. Jurnal Inovasi Pendidikan IPA, 3(2), 161. https://doi.org/10.21831/jipi.v3i2.15667.

Rigianti, H. A. (2020). Kendala Pembelajaran Daring Guru Sekolah Dasar di Banjarnegara. Elementary School: Jurnal Pendidikan Dan Pembelajaran Ke-SD-An, 7(2). https://doi.org/10.31316/esjurnal.v7i2.768.

Rosyada, M. I., Atmojo, I. R. W., \& Saputri, D. Y. (2021). Dampak Implementasi Pembelajaran dalam Jaringan (Daring) mengenai Kualitas Pembelajaran IPA di Sekolah Dasar pada Masa Pandemi Covid-19. In Didaktika Dwija Indria (Vol. 9, Issue 4). https://doi.org/10.20961/DDI.V9I4.49180.

Setiadi, H. (2019). Tantangan Revolusi Industri 4.0 : Pembelajaran Abad 21 Di SMK. Prosiding Seminar Nasional Teknologi Pendidikan Pascasarjana UNIMED, 3(5), 395-401. http://digilib.unimed.ac.id/38811/3/ATP 48.pdf.

Setiyoaji, W. T., Supriana, E., \& Laksono, Y. A. (2020). Pengembangan E-Book Berbasis Android dengan Soal HOTS untuk Membantu Menganalisis Besaran pada Materi Gerak Lurus. Jurnal Pendidikan Fisika Dan Teknologi, 6(1), 114. https://doi.org/10.29303/jpft.v6i1.1725. 
Shinde, V. V., \& Inamdar, S. S. (2013). Problem Based Learning (PBL) for Engineering Education in India: Need and Recommendations. Wireless Personal Communications, 69(3), 1097-1105. https://doi.org/10.1007/s11277-013-1069-0.

Sintia, R., Abdurrahman, \& Wahyudi, I. (2015). Pengembangan LKS Model Discovery Learning melalui Pendekatan Saintifik Materi Suhu dan Kalor. Jurnal Pembelajaran Fisika, 3, 125-134. http://jurnal.fkip.unila.ac.id/index.php/JPF/article/view/8485.

Siswanto, B. T. (2012). Pengaruh Model Penyelenggaraan Work-Based Learning Rolling Terpadu terhadap Aspek-Aspek Kualitas Hasil Belajar. Jurnal Pendidikan Teknologi Dan Kejuruan, 21(1), 67-73. https://dx.doi.org/10.21831/jptk.v21i1.3341.

Sugiyono. (2014). Metode Penelitian Pendidikan Pendekatan Kuantitatif, Kualitatif, dan R\&D. Alfabeta.

Wahyuni, I. (2018). Pemilihan Media Pembelajaran. Jurnal Pendidikan, 1(1), 1-11.

Walid, M., Saragih, M. R., Kunci, K., Organisasi, B., Guru, K., Usman, K., Yusrizal, I., Ibrahimii, S., Darmada, I. K., Dantes, N., Natajaya, N., Suryadinata, L. F., Agam, F., Suparman, L., \& Kerja, B. (2013). Kontribusi Kompetensi Manajerial Kepala Sekolah, Iklim Kerja dan Motivasi Kerja terhadap Kinerja Guru SMP Negeri se-Kecamatan Mendoyo Kabupaten Jembrana. Jurnal Magister Manajemen Universitas Mataram, 3(2), 1-25. https://doi.org/10.21831/economia.v9i2.1809.

Wijayanengtias, M., \& Claretta, D. (2020). Student Perceptions of Online Learning during the Covid-19 Pandemic. Kanal: Jurnal Ilmu Komunikasi, 9(1), 16-21. https://doi.org/10.21070/kanal.v9i1.685. 